\title{
ALGUNS ASPECTOS DA BIOLOGIA DE LYMNAEA COLUMELLA SAY, 1817 (GASTROPODA, PULMONATA)
}

Ueta, M. T. - Alguns aspectos da biologia de Lymnaea columella Say, 1817 (Gastropoda, Pulmonata). Rev. Saúde públ., S. Paulo, 10:355-66, 1976.

Resumo: Foram estudados aspectos da biologia da Lymnaea columella Say, 1817, em condiçôes de laboratório e determinadas as variações da duração do periodo embrionário em relação à temperatura da água.

UNITErmos: Lymnaea columella. Incubação, ovos. Fasciolose.

\section{INTRODU C A O}

0 interesse pelo estudo dos moluscos Lymnaeidae no Brasil vem crescendo desde a descrição de casos humanos autoctones de fasciolose (Rey ${ }^{19}$, 1958; Santos e Vieira ${ }^{21}$, 1965/67; Santos, apud Mattar Filho e Amaral ${ }^{15}$, 1967; Corrêa e Fleury ${ }^{7}, 1971$ ).

Em todas as regiões onde ocorre a fasciolose, os Lymnaeidae são incriminados como hospedeiros intermediários. No Brasil foram descritos como vetores da Fasciola hepatica moluscos do gênero Lymnaea (Lutz ${ }^{14}, 1921$; Santos e França, apud Corrêa e Fleury $\left.{ }^{7}, 1971\right)$. Mais recentemente, Rezende et al. ${ }^{20}$ (1973) no Rio de Janeiro, e Gonzales et al. ${ }^{11}$ (1974) no Rio Grande do Sul assinalaram espécimens de Lymnaea columella naturalmente infectados.

Lymnaea columella tem sido largamente estudada por vários autores, não somente em relação ao seu comportamento frente a infecção pelos trematódeos
(Krull ${ }^{12}, 1933$; Alicata ${ }^{1}, 1953$; Rezende et al. ${ }^{20}$, 1973; Gomes et al. ${ }^{9}, 1974$ ) como também sob o aspecto estritamente biológico, principalmente, no que diz respeito à capacidade de auto-reprodução, uma vez que nesta espécie a autofecundação constitui processo habitual de reprodução (Colton ${ }^{3}$, 1908; Colton ${ }^{4}$, 1912; DeWitt e Sloan ${ }^{8}$, 1958; Léon-Dancel ${ }^{13}$, 1970; Gomes et al. ${ }^{10}$, 1975).

Em nosso país, os estudos sobre a biologia dos caramujos transmissores da fasciolose são escassos e bastante recentes, pois até 1964 não havia registro de trabalhos referentes aos aspectos biológicos destes moluscos (Penna e Leme ${ }^{18}$ ). Somente em 1975 é que foram publicados estudos sobre a biologia destes caramujos.

Os objetivos deste trabalho foram estudar a fecundidade, fertilidade, duração do periodo embrionário e verificar a influência da temperatura sobre o período de desenvolvimento do embrião. A luminosi-

\footnotetext{
* Do Departamento de Parasitologia do Instituto de Biologia da Universidade de Campinas
} (UNICAMP) - Caixa Postal 1170 - Campinas, SP - Brasil. 
UETA, M. T. - Alguns aspectos da biologia de Lymnaea collmella Say, 1817 (Gastropoda, Pulmonata,. Rer. Saúle públ, S. Paulo, 10:355-66. 1976.

dade. $\mathrm{pH}$ da água e alimentação foram mantidas sob controle.

\section{MATERIAL E MÉTODOS}

Tossas observações sobre estes aspectos da hiologia abrangem um período de 10 meses ( novembro a dezembro de 1969; janeiro a março e julho a novembro de 1970 , * sendo incluídos nos estudos exemplares medindo entre $10.2 \mathrm{~mm}$ a 13,8 $\mathrm{mm}$. com uma média de $12.3 \mathrm{~mm}$ de comprimento. coletados de vários tipos de criadouros com lagoas e córregos, nas proximidades da cidade de Campinas.

Os caramujos foram mantidos em beakers de $600 \mathrm{ml}$. cobertos com gaze, contendo aproximadamente $400 \mathrm{ml}$ de água não tratada. recehendo. uma vez por semana. pequenas quantidades de carbonato de cálcio. Não utilizamos substrato arenoso ou lodoso a fim de que fosse facilitada a observaçãa das desovas. tampouco foram colocadas plantas aquáticas. Desse modo evitamos posturas de cápsulas oviferas nas folhas das plantas, o que dificultaria nossa observação. A água dos frascos era trocada semanalmente para impedir acúmulo de detritos orgânicos. O desenvolvimento de algas foi controlado raspando-se a parede dos frascos quando havia excessiva multiplicação destes vegetais.

Para alimentação dos adultos foram utilizadas folhas de alface fresca em pequenas porções e o excesso era retirado diariamente. Os caramujos jovens alimentavam-se. nos primejros dias. de algas que se desenvolviam nas paredes dos frascos e após alguns dias já consumiam alface tenra.

A fim de facilitar a observação das desovas foram colocados pequenos retângulos de plástico, de aproximadamente 4.0 $x 4.5 \mathrm{~cm}$ (Olivier et al. $\left.{ }^{17}, 1962\right)$ onde. na maioria dos casos os caramujos depositavam as cápsulas ovíferas. Outras vezes as desovas eram encontradas nas paredes dos frascos ou sobre outros caramujos. Os plásticos, contendo as desovas, eram transferidos para outros beakers menores contendo água e mantidos sob constante observação.

As cápsulas ovíferas foram medidas em milimetros e contados o número de ovos no seu interior.

A fecundidade dos caramujos foi determinada tomando-se o número de cápsulas ovíferas e de ovos por caramujo e a fertilidade por intermédio de taxa de eclosão e percentagem de ovos férteis por caramujos, considerando-se como ovos férteis aqueles que apresentaram massa embrionária.

A duração do período embrionário foi estabelecida em dias. contados desde a postura até a eclosão dos caramujos. Foi utilizado o teste " $t$ " de Student para avaliar as diferenças entre as médias obtidas. A duração do período embrionário e a percentagem de eclosão dos ovos foram correlacionados com a temperatura da água, temperaturas máxima e mínima e umidade relativa do ar. Foram feitos testes de correlação parcial entre o período embrionário e os fatores externos.

As desovas de vários indivíduos foram agrupadas por mês em que foram ovipostas.

$0 \mathrm{pH}$ dos frascos foi medido, diariamente. com papel de tormassol.

A temperatura da água dos beakers e a umidade relativa do ar era tomada 4 vezes ao dia. A temperatura ambiente foi anotada cada 24 horas. utilizando-se termômetro de máxima e mínima.

\section{RESLLTADOS}

Pelo método de criação e manutenção utilizado obtivemos 4 gerações em laboratório. * Vão foi possivel realizar observasóes das desovas entre abril e junho. por motivos de
ordem técnica. 
LETA, M. T. - Alguns aspectos da biologia de Lymnaea columella Say, 1817 (Gastropoda. Pulmonata). Rei. Saude ptibl, S. Paulo, 10:355-66, 1976.

De um total de 113 caramujos, obser- Estes resultados, agrupados mensalmente, rados durante a experiência, foram obtidas 391 cápsulas ovíferas contendo um total de 6.464 oros.

As cápsulas ovíferas variaram de 2,5 $\mathrm{mm}$ a $14.0 \mathrm{~mm}$ de comprimento por 1.5 $\mathrm{mm}$ a $4.5 \mathrm{~mm}$ de largura, respectivamente. com médias de $9.3 \mathrm{~mm}$ e $2.6 \mathrm{~mm}$.

estão registrados na Tabela 1 .

O número médio de cápsulas ovíferas por caramujo foi de 3.5 e o número médio de ovos por cápsula foi de 16,5 variando desde 1 a 41 ovos por desova, dependendo do tamanho do caramujo e da sua idade.

$T A B E I A \quad 1$

Número de cápsulas oviferas de $L$. columella observadas e suas dimensōes

\begin{tabular}{|c|c|c|c|c|c|}
\hline $\begin{array}{l}\text { Periodo de } \\
\text { observação }\end{array}$ & $\begin{array}{l}\text { N.o total } \\
\text { de cápsulas } \\
\text { oviferas }\end{array}$ & $\begin{array}{l}\text { Cápsula } \\
\text { ovifera por } \\
\text { caramujo }\end{array}$ & $\begin{array}{l}\text { Cápsula } \\
\text { ovifera por } \\
\text { caramujo } \\
\text { por dia }\end{array}$ & $\begin{array}{l}\text { Comprimento } \\
\text { da cápsula } \\
\text { ovífera (mm) } \\
\text { média }\end{array}$ & $\begin{array}{c}\text { Largura } \\
\text { da cápsula } \\
\text { ovifera (mm) } \\
\text { média. }\end{array}$ \\
\hline Novembro-69 & 19 & 4.8 & 0,4 & $9,2 \pm 0,28$ & $2,2 \pm 0,10$ \\
\hline Dezembro & 33 & 8,3 & 0,3 & $9,5 \pm 0,42$ & $2,2 \pm 0,06$ \\
\hline Janeiro-70 & 12 & 6,0 & 0,2 & $7,4 \pm 0,43$ & $1,8 \pm 0,10$ \\
\hline Fevereiro & 42 & 6,0 & 1,5 & $9,7 \pm 0,39$ & $2,2 \pm 0,07$ \\
\hline Março & 24 & 3.4 & 0,3 & $8,9 \pm 0,52$ & $2.2 \pm 0,07$ \\
\hline Julho & 21 & 3,0 & 0.2 & $9,2 \pm 0,46$ & $2,3 \pm 0,11$ \\
\hline Agosto & 29 & 4.8 & 0,2 & $9,5 \pm 0,44$ & $2,5 \pm 0,11$ \\
\hline Setembro & 17 & 3,4 & 0,1 & $8,1 \pm 0,54$ & $2,8 \pm 0,18$ \\
\hline Outubro & 137 & 3,7 & 0.1 & $9,2 \pm 0,19$ & $2,8 \pm 0,07$ \\
\hline Novembro & 57 & 1,7 & 0,2 & $9,3 \pm 0,34$ & 3,2 士 0,10 \\
\hline Média geral & & $3, \overline{5}$ & & $9.3 \pm 0.44$ & $2.6 \pm 0.12$ \\
\hline
\end{tabular}

TABEL 2

Número de ovos de $L$. columella observados durante a experiênela

\begin{tabular}{|c|c|c|c|c|c|c|c|c|}
\hline $\begin{array}{l}\text { Periodo de } \\
\text { observação }\end{array}$ & N.O total & $\begin{array}{l}\text { Oros por } \\
\text { cápsula }\end{array}$ & $\begin{array}{l}\text { Ovos por } \\
\text { caramujo }\end{array}$ & $\begin{array}{l}\text { Ovos por } \\
\text { caramujo } \\
\text { por dia }\end{array}$ & $\begin{array}{l}\text { Ovos } \\
\text { férteis }\end{array}$ & $\begin{array}{l}\text { co de } \\
\text { ovos } \\
\text { férteis }\end{array}$ & $\begin{array}{l}\text { No de } \\
\text { ovos } \\
\text { eclodidos }\end{array}$ & $\begin{array}{c}\% \text { de } \\
\text { ovos } \\
\text { eclodidos }\end{array}$ \\
\hline Novembro-69 & 267 & 14.1 & 66,8 & 6,1 & 260 & 97,4 & 254 & 97.7 \\
\hline Dezembro & 412 & 12,5 & 103,0 & 3,4 & 409 & 99,3 & 391 & 95,6 \\
\hline Janeiro- 70 & 130 & 10,8 & 65,0 & 2,6 & 130 & 100,0 & 130 & 100,0 \\
\hline Feverejro & 524 & 12.5 & 74,9 & 18.7 & 523 & 99.8 & 513 & 98,1 \\
\hline Marco & 250 & 10,4 & 35,7 & 3,6 & 250 & 100,0 & 249 & 99,6 \\
\hline Julho & 267 & 12,7 & 38,1 & 2,5 & 266 & 99,6 & 240 & 90,2 \\
\hline Agosto & 395 & 13,6 & 65,8 & 2,3 & 393 & 99,5 & 378 & 96,2 \\
\hline Setembro & 256 & 15,1 & 51,2 & 1,8 & 256 & 100,0 & 237 & 92,6 \\
\hline Outubro & 2.821 & 20,6 & 76,2 & 2.5 & 2.819 & 99,9 & 2.779 & 98,6 \\
\hline Novembro & 1.142 & 20,0 & 33,6 & 4,8 & 1.134 & 99,3 & 1.125 & 99,2 \\
\hline Média geral & & 16,5 & & & & 99.6 & & 97,8 \\
\hline
\end{tabular}


LETA, M. T. - Alguns aspectos da biologia de Lymnaea columella Say, 1817 (Gastropoda, Pulmonata). Rev. Saúde pübl., S. Paulo, 10:35̃-66, 1976.

O número de ovos férteis nas desovas observadas é extremamente alto, alcançando um percentual de $99.6 \%$, o que representa a quase totalidade dos ovos eliminados pelo caramujo. Destes ovos, a grande maioria desenvolveu-se satisfatoriamente, totalizando $97.8 \%$ de caramujos eclodidos (calculados sobre o total de oros férteis). Normalmente cada oro possui um embrião, mas podem ocorrer gêmeos. Em um total de 2.899 ovos, a percentagem com 2 embriōes foi de $1,8 \%$, e a ocorrência com 3 ou mais embrióes foi extremamente rara, correspondendo a apenas $0,4 \%$. Os resultados reunidos por mês estão expressos na Tabela 2.

As percentagens de eclosão dos ovos relacionados com os fatores ambientes estão na Tabela 3 , podendo-se verificar que a correlação não é significante ao nivel de $5 \%$, para temperatura máxima ambiente e para umidade relativa do ar. Houre fraca correlação direta entre a percentagem de eclosão dos ovos e a temperatura da água e com a temperatura mínima ambiente (Fig. 1).

\section{TAB E L A 3}

Coeficiente de correlação entre percentagem de eclosão dos ovos de $L$. columella e fatores ambientes

\begin{tabular}{l|c}
\hline Fatores ambientes & Valores de " $\mathrm{r} "$ \\
\hline Temp. máxima - média & 0,6120 \\
Temp. minima - média & $0,7066^{*}$ \\
Temp. água - média & $0,7214^{*}$ \\
Umidade relativa & 0,5934 \\
\hline
\end{tabular}

* Significância ao nível de $5 \%$.

A duração média do período embrionário variou de 10.5 a 16.9 dias (Tabela 4.). Foram testadas as diferenças das médias pelo teste " $t$ " (Tabela 5 ), observan-
TABELA 4

Duração média do periodo embrionário em dias de $L$. columella

\begin{tabular}{|c|c|c|}
\hline $\begin{array}{l}\text { Periodo de } \\
\text { observação }\end{array}$ & $\begin{array}{l}\text { No total } \\
\text { de cápsulas } \\
\text { oviferas }\end{array}$ & $\begin{array}{l}\text { Periodo } \\
\text { embrio- } \\
\text { nário em } \\
\text { dias - } \\
\text { média }\end{array}$ \\
\hline Niovembro-69 & 19 & $13,9 \pm 0,34$ \\
\hline Dezembro & 33 & $13,4 \pm 0,43$ \\
\hline Janeiro-70 & 12 & $10,5 \pm 0,92$ \\
\hline Fevereiro & 42 & $11,9 \pm 0,46$ \\
\hline Março & 24 & $10,5 \pm 0,65$ \\
\hline Julho & 21 & $16,9 \pm 0,60$ \\
\hline Agosto & 29 & $16,9 \pm 0,68$ \\
\hline Setembro & 17 & $14,7 \pm 0,42$ \\
\hline Outubro & 137 & $12,3 \pm 0,40$ \\
\hline Novembro & 57 & $14,0 \pm 0,41$ \\
\hline
\end{tabular}

TABELA 5

Resultados do teste " $t$ " realizado entre as médias da duração do periodo embrionário de $L$. columella expressas por mês

\begin{tabular}{l|l}
\hline \multicolumn{1}{c|}{ NIeses } & Valor de "t" \\
\hline Janeiro - Julho & $\mathbf{5 , 5 6 *}$ \\
Janeiro - Dezembro & $\mathbf{3 , 3 0 *}$ \\
Janeiro - Outubro & $\mathbf{1 , 8 0}$ \\
Janeiro - Novembro & $4,36 *$ \\
Janeiro - Fevereiro & $1,44^{*}$ \\
Fevereiro - Dezembro & $2,31^{*}$ \\
Julho - Setembro & $2,09^{*}$ \\
Setembro - Outubro & $2,53^{*}$ \\
Outubro - Novembro & $2,66 *$ \\
Outubro - Dezembro & 1,64 \\
Setembro - Dezembro & 1,83 \\
\hline
\end{tabular}

* Significância ao nivel de $5 \%$.

do-se que entre algumas médias ocorreram diferenças significativas. Não houve diferença significativa, ao nível de $5 \%$, entre as médias correspondentes aos meses de janeiro, fevereiro e março, quando a temperatura média da água variou de $26.8^{\circ} \mathrm{C}$ a $27.9^{\circ} \mathrm{C}$. Não houve também diferença significativa das médias entre os 
LETA, M. T. - Alguns aspectos da biologia de Lymnaea columella Say, 1817 (Gastropoda, Pulmonata). Rev. Saúde públ., S. Paulo, 10:355-66, 1976.

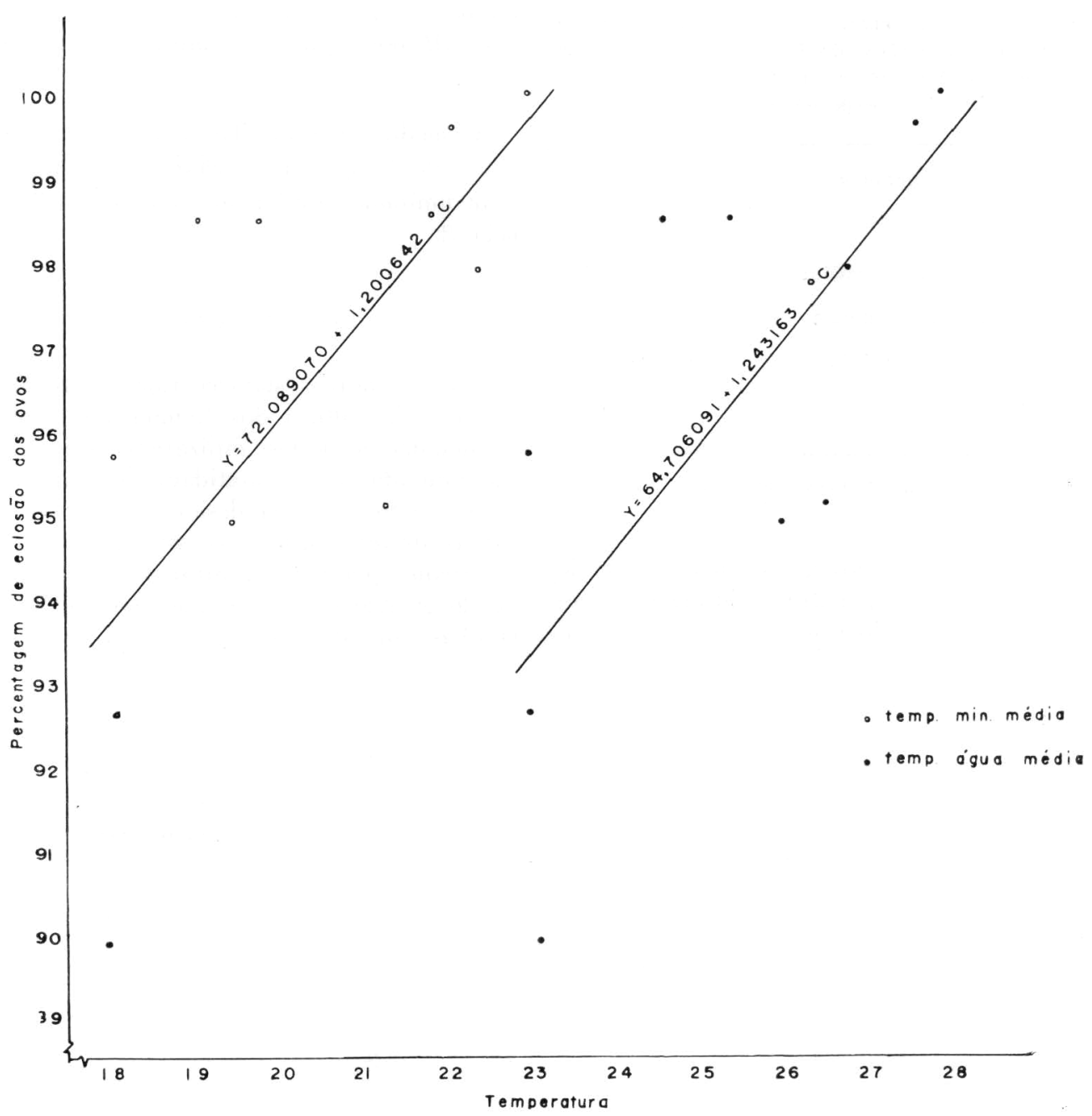

Fig. 1 - Relaçōes entre percentagem de eclosão dos ovos de $L$. columella e temperaturas da água e mínima ambiente.

três primeiros meses do ano e outubro que registrou a média de $25,4^{\circ} \mathrm{C}$ para a temperatura da água.

As médias dos meses de julho e agosto apresentaram-se significativamente diferentes, ao nível de $5 \%$, das de janeiro a março e outubro, mas diferiram fraca- mente da de setembro, embora a temperatura média da água deste último mês tenha sido a mesma das de julho e agosto.

Da correlação do período embrionário com a temperatura média da água e demais fatores, resultou um coeficiente de correlação inversa altamente significativo (Tabela 6 e Figs. 2 e 3). 
UETA, M. T. - Alguns aspectos da biologia de Lymnaea columella Say, 1817 (Gastropoda. Pulmonata). Rev. Saúde públ., S. Paulo, 10:355-66, 1976.

\section{TA B E A 6}

Coeficientes de correlação entre duração do período embrionário de $L$. columella e fatores ambientes observados durante o período da experiência

\begin{tabular}{l|r}
\hline \multicolumn{1}{c|}{ Fatores ambientes } & Valor de " $r "$ \\
\hline \hline Temp. máxima - média & $-0,8437^{*}$ \\
Temp. minima - média & $-0,8718^{*}$ \\
Temp água - média & $-0,9074^{*}$ \\
Limidade relativa & $-0,8660^{*}$ \\
\hline
\end{tabular}

* Significáncia ao nivel de $\mathbf{5} \%$.

A Tabela 7 mostra os coeficientes de correlação parcial entre a duração do período embrionário e temperatura da água, temperatura máxima e mínima e com umidade relativa do ar.

$\mathrm{O} \mathrm{pH}$ dos aquários manteve-se em torno de 7 .

As médias mensais das temperaturas da água. da temperatura máxima e mínima e da umidade relativa do ar estão na $\bar{T}^{-}$ hela 8 .

\section{DISCUSSA O}

Vários autores estabeleceram diferentes métodos de cultura dos Lymnaeidae, mas essencialmente todos utilizaram recipientes contendo certa quantidade de água de fonte, de torneira ou desionizada, conforme as preferências e necessidades. Esses recipientes por vezes continham terra, podendo ou não serem arejados por meio de hombas ou através do uso de plantas

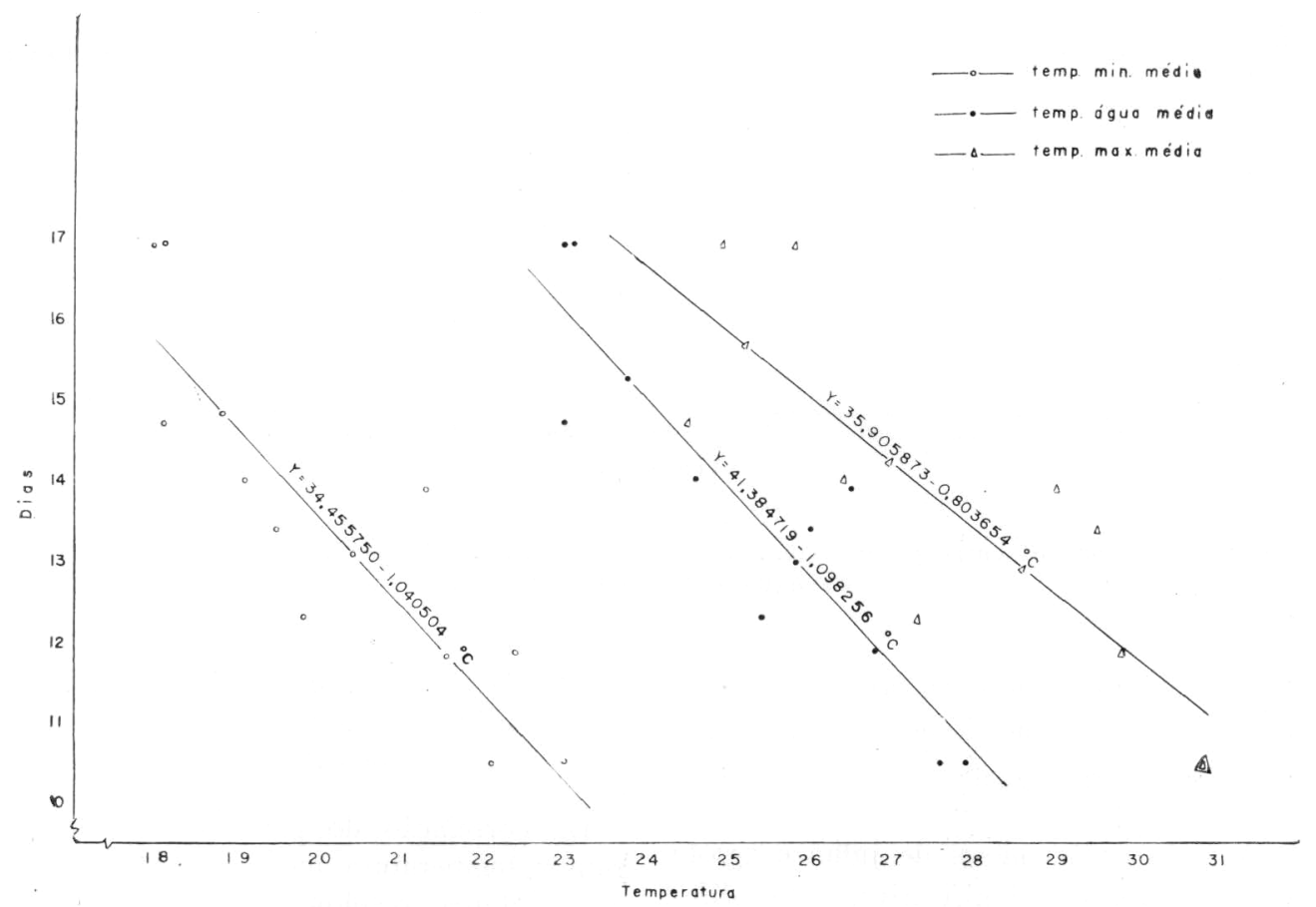

Fig. 2 - Representação gráfica do coeficiente de correlação entre periodo embrionário de $L$. columella e temperatura da água, temperaturas máxima e minima do ar. 
UETA. II. T. - Aiguns aspectos da biologia de Lymnaea columella Say, 1817 (Gastropoda, Pulmonata). Rer saúde pübl, s Paulo, 10:355-66. 1976.

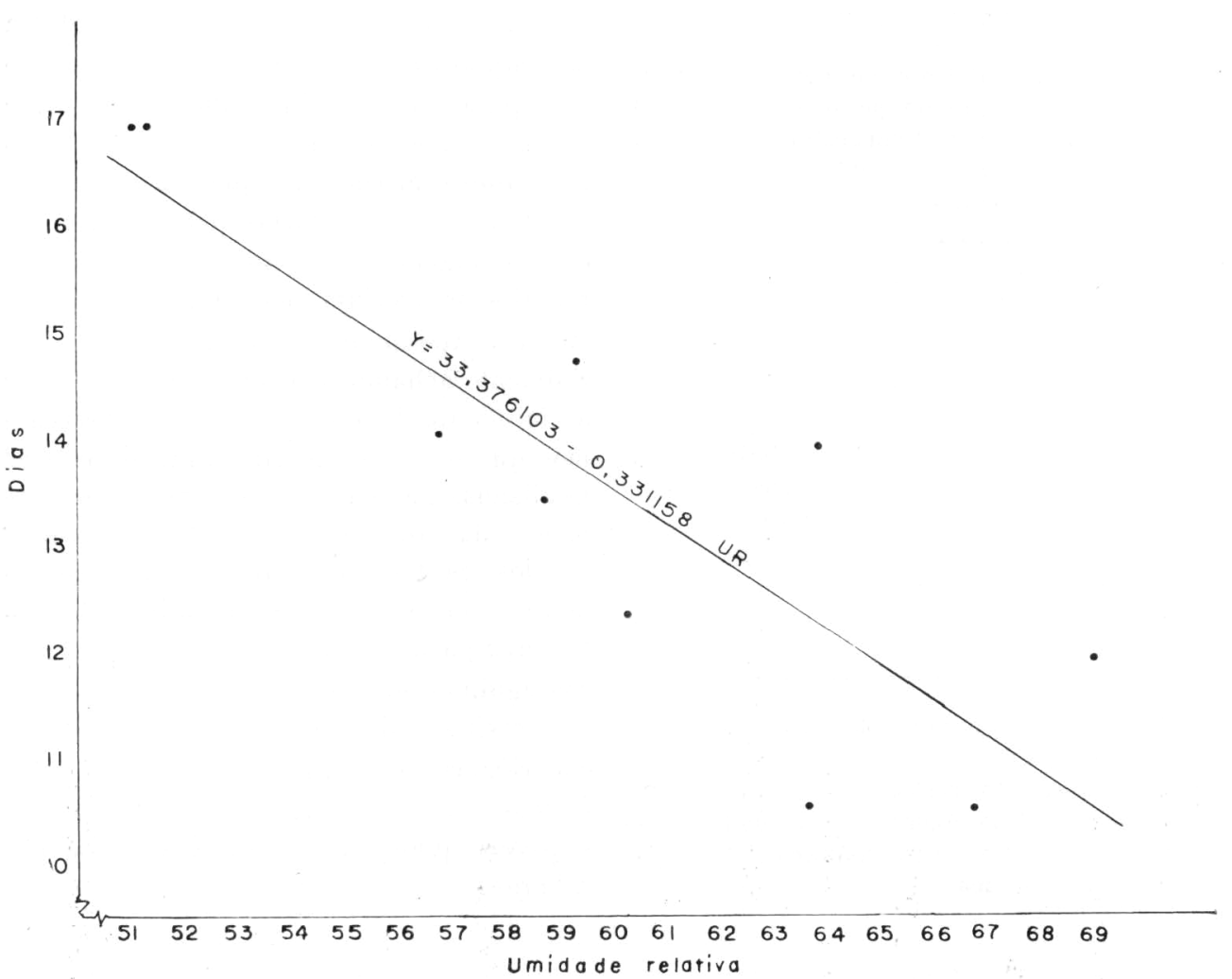

Flg 3 - Relação da duração do periodo embrionárı de $L$ columella e umidade relativa do al.

aquáticas. Os aquários eram mantidos à temperatura ambiente ou em recintos com condições controladas.

Taylor e Mozley: (1948). idealizaram um método de cultura para Lymnaea truncatula. com excelentes resultados. A partir desta data vários autores realizaram experiências sobre a biologia dos Lymnaeidae baseados nesse método. com modificações julgadas convenientes de acordo com os objetivos das experiências. Mazzotti ${ }^{16}$ (1955) utilizou em certas experiências um recipiente contendo pedras e pedaços de tijolo. de tal modo. que estas sobressaíssem da água e cuidou para que se formasse uma ligeira correnteza utilizando para isso um tubo horizontal com perfuraçôes. Segundo este autor, o escorrer constante da água foi favorável aos caramujos. pois houve acúmulo dos mesmos nas pedras e tijolos onde caía a água, talvez devido ao desenvolvimento maior das algas nestes locais. Após um ano. com este método de cultura. o autor ohteve grande aumento da população de caramujos. Mazzotti ${ }^{16}$ utilizou. posteriormente. frascos de harro contendo terra do próprio local onde foram coletados os caramujos e empregou hombas para o arejamento dos frascos.

O método empregado por nós não diferiu muito dos demais com a vantagem de ter permitido a ohservação do interior dos frascos por transparência. Colton e Pennypacker" 11934$)$ preconizaram a neces- 
LETA, M. T. - Alguns aspectos da biologia de Lymnaea columella Say, 1817 (Gastropoda. Pulmonata). Rev. Saúde puibl., S. Paulo, 10:355-66, 1976.

\section{TABELA 7}

Resultados do coeficiente de correlação parcial entre a duração do periodo embrionário de $L$. columella e a temperatura da água, temperatura máxima e minima e umidađe relativa do ar

\begin{tabular}{c|c}
\hline $\begin{array}{l}\text { Correlacão parcial } \\
\text { entre os fatores }\end{array}$ & Valor de " $r$ " parcial \\
\hline & $r_{12,3} *$ \\
$r_{13,2}$ & $-0,6598^{*}$ \\
$r_{23,1}$ & $-0,4482$ \\
$r_{14,3}$ & 0,2510 \\
$r_{43,1}$ & $-0,5274$ \\
$r_{15,3}$ & $-0,2058$ \\
$r_{13,5}$ & $-0,4628$ \\
$r_{35,1}$ & 0,5085 \\
\hline
\end{tabular}

* Significância ao nível de 10\%.

* 1. duração do período embrionário; 2. temperatura da água; 3 . umidade rela. tiva; 4. temperatura máxima; 5. temperatura minima. sidade de se colocar um pouco de terra nos aquários para que as partículas do solo pudessem ser ingeridas pelos caramujos e armazenados no estômago. Estes autores afirmaram que as pedras no estômago são necessárias para triturar os tecidos vegetais, pois do contrário os caramujos morreriam pela não digestão do amido. Apesar desta recomendação, inicialmente achamos conveniente não colocar areia no fundo dos frascos por observarmos que os grãos danifacavam as desovas localizadas nas paredes dos frascos no momento da troca de água. Os caramujos criados nestas condições mantiveram-se muito bem por um periodo suficientemente longo para atingirem a maturidade, pois conseguimos mantê-los em laboratório por 4 gerações. Mais tarde, no decorrer da experiência, colocamos areia em vários frascos, não tendo sido notadas diferenças sensíveis quanto à sobrevivência dos caramujos.

\section{TABELA 8}

Temperatura e umidade relativa do ar e temperatura da água registradas durante o período de observaçāo (1969-1970)

\begin{tabular}{|c|c|c|c|c|}
\hline \multirow{3}{*}{$\begin{array}{l}\text { Periodo de } \\
\text { observação }\end{array}$} & \multicolumn{3}{|c|}{ Temperatura $\left({ }^{\circ} \mathrm{C}\right)$} & \multirow{3}{*}{$\begin{array}{l}\text { Umidade } \\
\text { relativa }(\%) \\
\text { (média) }\end{array}$} \\
\hline & \multicolumn{2}{|c|}{ Ambiente } & \multirow{2}{*}{$\begin{array}{c}\text { Ãgua } \\
\text { (média) }\end{array}$} & \\
\hline & $\begin{array}{l}\text { Máxima } \\
\text { (média) }\end{array}$ & $\begin{array}{l}\text { Mínima } \\
\text { (média) }\end{array}$ & & \\
\hline Novembro-69 & 29,0 & 21,3 & 26,5 & 63,8 \\
\hline Dezembro & 29,5 & 19,5 & 26,0 & 58,7 \\
\hline Janeiro-70 & 30,8 & 23,0 & 27,9 & 63,6 \\
\hline Fevereiro & 29,8 & 22,4 & 26,8 & 68,9 \\
\hline Marso & 30,8 & 22,1 & 27,6 & 66,7 \\
\hline Julho & 25,8 & 18,0 & 23.1 & 51,3 \\
\hline Agosto & 24,9 & 18,1 & 23,0 & 51,0 \\
\hline Setembro & 24,5 & 18,1 & 23,0 & 59,3 \\
\hline Outubro & 27,3 & 19,8 & 25,4 & 60,2 \\
\hline Novembro & 26,4 & 19.1 & 24,6 & 56,7 \\
\hline
\end{tabular}


LETA, M. T. - Alguns aspectos da blologia de Lymnaea columella Say, 1817 (Gastropoda, Pulmonata). Rev. Saúde públ., S. Paulo, 10:355-66, 1976.

Combrinck e van Eeden ${ }^{6}$ (1969) verificaram que a microflora do aquário exerce maior influência sobre o crescimento da população de moluscos do que o tipo de substrato utilizado. Baseados nestas observações, não usamos terra colhida nos criadouros de limneideos.

Os caramujos trazidos do campo e mantidos nas condições da experiência, apresentavam elevada taxa de mortalidade, embora ovipusessem intensamente.

Dos vários autores que realizaram pesquisas sobre aspectos da biologia dos caramujos, somente Léon-Dancel ${ }^{13}$ (1970) e Gomes et al. ${ }^{10}$ (1975) fizeram observaçōes sobre as dimensões das cápsulas ovíferas, obtendo, respectivamente, as seguintes medidas: $6,0-9,0 \mathrm{~mm}$ de comprimento por $3,0-4,0 \mathrm{~mm}$ de largura com uma média de 19 ovos, e 4,0 - 12,0 $\mathrm{mm}$ de comprimento e $3,0-5,0 \mathrm{~mm}$ de largura, com uma média de 18 ovos por cápsula. Nos nossos resultados as amplitudes do comprimento e largura das cápsulas ovíferas são maiores, com uma média menor de número de ovos por cápsula. Obtivemos, portanto, em média, cápsulas mais longas, mais estreitas com menor número de ovos. Baily Jr. ${ }^{2}$ (1931) já sugeria em suas pesquisas uma correlação positiva entre tamanho de cápsula ovífera e tamanho da concha, de modo que acreditamos que as pequenas diferenças obtidas por nós e pelos autores mencionados devem-se aos tamanhos diferentes dos caramujos utilizados.

A média menor do número de ovos por cápsula pode ser explicada em virtude da grande variação que obtivemos ( 1 ovo a 41 ovos por cápsula ovífera). Nossas ob- servações corroboram as afirmações e sugestoes apresentadas por Baily $\mathrm{Jr}^{2}{ }^{2}$ (1931) em suas conclusões. Segundo este autor a produção de ovos está diretamente correlacionada com tamanho da concha e com a duração da vida do molusco. Haveria ainda evidências da correlação, também positiva, entre o número médio de ovos por desova, e o tamanho da concha. León-Dancel ${ }^{13}$ (1970) confirmou o aumento progressivo do tamanho da cápsula ovífera e o número de ovos dentro das cápsulas, à medida que o caramujo crescia.

A produção média de ovos por caramujo por dia foi inferior aos resultados obtidos por Léon-Dancel ${ }^{13}$ (1970) e Gomes et al. ${ }^{10}(1975)$.

Para estudos sobre desenvolvimento dos ovos, León-Dancel ${ }^{13}$ (1970) e Gomes et al. ${ }^{10}$ (1975) retiraram as cápsulas oviferas das paredes dos frascos e colocaramnas em placas de Petri com papel de filtro umedecido. Obiveram $98-100 \%$ de ovos eclodidos à temperatura ambiente de $26^{\circ}-28^{\circ} \mathrm{C}$ e $96-100 \%$ à temperatura ambiente de $27^{\circ}-29^{\circ} \mathrm{C}$, respectivamente. A percentagem de eclosão obtida por estes dois autores coincide com a obtida por nós, para os meses mais quentes. Com exceção da percentagem obtida no mês de agosto, os meses de julho e setembro registraram índices mais baixos de eclosão de ovos.

Através dos dados obtidos concluímos que há uma nítida correlação inversa entre o número de dias necessários para eclosão dos ovos e a temperatura da água, o que significa que para os meses mais frios, como julho e agosto, os embrióes 
UETA, M. T. - Alguns aspectos da biologia de Lymnaea columella Say, 1817 (Gastropoda, Pulmonata). Rev. Saúde pübl., S. Paulo, 10:355-66, 1976.

necessitam maior número de dias para completar seu desenvolvimento. A média da temperatura da água no mês de setembro foi a mesma da dos meses de julho e agosto, mas houve diferença fracamente significativa entre a duração do período embrionário nesses meses.

Uma vez que Colton e Pennypacker 5 (1934) já haviam constatado em condiçōes padronizadas, variações de 8 a 12 dias necessários para o desenvolvimento do embrião, podemos compreender nossos dados referentes aos meses de julho, agosto e setembro, quando para uma temperatura média da água de $23^{\circ} \mathrm{C}$ obtivemos dados referentes à duração do período embrionário que diferiram significativamente.

A duração do período embrionário obtida quando a temperatura da água variou de $24,5^{\circ}$ a $28^{\circ} \mathrm{C}$, com a temperatura do ar entre $24^{\circ}$ a $27^{\circ} \mathrm{C}$, foi de 10,5 a 14,0 dias. Houve concordância com os resultados obtidos por León-Dancel ${ }^{13}$ (1970) que obteve 10,0 a 13,0 dias para temperatura ambiente de $26^{\circ}$ a $28^{\circ} \mathrm{C}$. A duração do periodo embrionário obtida por Gomes et al. ${ }^{10}$ (1975) foi um pouco menor, variando de 9,0 a 12,0 dias para a temperatura média de 27 a $29^{\circ} \mathrm{C}$.
CONCLUSOES

1. O número e o tamanho das cápsulas ovíferas estão diretamente relacionados com o tamanho e maturidade dos caramujos, o que confirma as conclusões de Baily Jr. ${ }^{2}$ (1931).

2. Houve influência da temperatura da água na eclosão dos caramujos.

3. A duração do período embrionário variou em função da temperatura da água, apresentando uma correlação inversa bastante significativa. Os demais fatores influíram secundariamente, sempre em relação com a temperatura da água.

4. O emprego de diferentes métodos de manutenção dos ovos até a eclosão parece não ter influído na duração do período embrionário.

\section{A G R A D E I M E N TOS}

Ao Professor Aquiles E. Piedrabuena pela colaboração prestada nos cálculos estatísticos e aos Professores Luiz A. Magalhães e Urara Kawazoe pela revisão e sugestöes apresentadas.

UETA, M. T. - [Some observations on the life-history of Lymnaea columella Say, 1817 (Gastropoda, Pulmonata)]. Rev. Saúde públ., S. Paulo, 10:355-66, 1976.

SUMmary: Some aspects on the life history of Lymnaea columella Say, 1817 were studied under laboratory conditions. The relationship between in. cubation period of the eggs and water temperature was established.

UnITERMS: Lymnaea columelia. Eggs incubation. Fasciolosis. 
LETA. M. T. - Alguns aspectos da biologia de Lymnaea columella Say, 1817 (Gastropoda, Pulmonata). Rev. Saude puibl., S. Paulo, 10:355-66, 1976.

\section{REFERENCIAS BIBLIOGRAFICAS}

1. AliCATA, J. E. - The snails, Pseudosuccinea columella (Say), new intermediate hosts for the liver fluke Fasciola gigantica Cobbold. J. Parasit., 39:673-4, 1953 .

2. BAILY Jr., J. L. - some data on growth, longevity, and fecundity in Lymnaea columella Say. Biol. gen., $7: 407-28,1931$.

3. COLTON, H S. - Some effects of environment on the growth of Lymnaea columella say. Proc. Acad. nat. Sci. Philadelphia, 60:410-48, 1908.

4. COLTON, H. S. - Lymnaea columella, and self-fertilization. Proc. Acad. nat. Sci. Philadelphia, 64:173-83, 1912 .

5. COLTON, H. S. \& PENNYPACKER, M. - The results of twenty years of self-fertilization in the pond snail Lymnaea columella Say. Amer, Nat., 68 (715):129-136, 1934 .

6. COMBRINCK, C. \& VAN EEDEN, J. A. - The influence of the substratum on population increase and habitat selection by Lymnaea natalensis $\mathrm{Krs}$. and Bulinus (B) tropicus Krs. (Mollusca, Basommatophora). Malacologia, $9(1): 39$, 1969. [Abstract Presented to Symposium on Molluscs as Parasites for their Transmitters, Vienna, 1968].

7. CORREA, M. O. A. \& FLEURY, G. C. - Fasciollase hepática humana: novo caso autóctone. Rev. Soc. bras. Med. trop., 5:267-70, 1971.

8. DeWITT, R. M. \& SLOAN, W. C. - The innate capacity for increase in numbers in the pulmonate snail, Lym. naea columella. Trans, Amer. Microsc. Soc., 77:290-4, 1958.

9. GOMES, P. A. C. et al. - Infecção experimental de Lymnaea columella Say, 1817, com Fasciola hepatica Linnaeus, 1758 , de ocorrencia no Estado do Rio de Janeiro. Arq. Unir. Fed. Rural. Rio de Janeiro, 4:35-8. 1974.
10. GOMES, P. A. C. et al. - Biologia da Lymnaea columella Say, 1817. Arq. Mus. Nac., Rio de Janeiro, 55:67-70, 1975 .

11. GONZALES, J. C. et al. - Lymnaea columella, hospedeiro intermediário de Fasciola hepatica (Lin. 1758) no Rio Grande do Sul, Brasil. Arq. Fac. Vet. UFRGS, Porto Alegre, 2:37-40, 1974.

12. KRULL, W. H. - The snail Pseudosuccinea columella (Say) as a potentially important intermediate host in extending the range of Fasciola hepatica Linn. J. Wash, Acad. Sol, 23:389-91, 1933.

13. LEÓN-DANCEL, D. - Life history of Lymnaea columella (Say) and its experimental infection with Fasciola hepatica (L.). J. Agr. Univ. Puerto Rico, 54:297-305, 1970.

14. LUTZ, A. - Sobre a ocorrencia da Fasciola hepatica no Estado do Rio de Janeiro. Bol. Inst. Oswaldo Cruz, $1: 9-13,1921$.

15. MATTAR F. ${ }^{\circ}$, J. A. \& AMARAL, A. D F. - Sobre um caso humano de fascioliase hepática Folia clinica et biol., S. Paulo, 36:56-67, 1967.

16. MAZZOTTI, L. - Lymnaea obrussa Say, huesped intermediario de Fasciola hepatica. Rev. Inst. Salubr. Enferm. trop., México, 15:163-5, 1955.

17. OLIVIER, $L$. et al. - The action of very low concentrations of sodium pentachlorophenate on freshly laid eggs of Australorbis glabratus. Bull. Wld Hith Org., 27:87-94, 1962.

18. PENNA, L. \& LEME, J. L. M. - Molus$\cos$ de água doce. apud VANZOLINI, P. E., ed. - História natural de organismos aquáticos do Brasil. São Paulo, Fundação de Amparo à Pesquisa do Estado de Săo Paulo, 1964. p. 253-264.

19. REY, L. et al. - Primeiro encontro de ovos de Fasciola hepatica em inquérito helmintológico de populaçōes brasileiras (Campo Grande, Mato Grosso). Rev. paul. Med., 53:60 1958. 
UETA, M. T. - Alguns aspectos da biologia de Lymnaea columella Say, 1817 (Gastropoda, Pulmonata), Rev. Saúde públ., S. Paulo, 10:355-66, 1976.

20. REZENDE, H. E. et al. - Notas sobre duas espécies de Lymnaea Lamark, 1799, hospedeiros intermediários de Fasciola hepatica L. no Estado do Rlo de Janeiro. (Mollusca, Gastropoda, Basommatophora, Lymnaeldae). Arq. Univ. Fed. Rural. Rio de Janeiro, 3:21-3, 1973.

21. SANTOS, L. \& VIEIRA, T. F. - Consideracōes sobre os sete primeiros casos de fasciolose humana encontrados no Vale do Paraiba, Estado de São Paulo. Rev. Inst. Adolfo Lutz, 25/27:95-109, 1965/67.

22. TAYLOR, E. L. \& MOZLEY, A. - A culture method for Lymnaea trunca. tula. Nature, 161:894, 1948.

Recebido para publicação em 09/04/1976 Aprovado para publicąão em 14/06/1976 